\title{
Factors Influencing Regular Mammography Screening Participation in a Sample of Turkish Women: Cross-Sectional Study
}

\author{
Filiz Okur RN ${ }^{1}$ and Zeynep Güneş PhD $^{2 *}$
}

\author{
${ }^{1}$ RN: Filiz Okur: Turkey Public Hospitals Authority, Turkey. \\ ${ }^{2}$ Associate Professor, Adnan Menderes University, Nursing \\ Faculy, Aydin, Turkey.
}

\author{
"Correspondence: \\ Zeynep Güneş PhD, Adnan Menderes University, Nursing Faculty \\ (Hemşirelik Fakültesi), Aydın, Turkey, E-mail: zeynepadu@gmail. \\ com/zeynep_adu@hotmail.com.
}

Received: 24 February 2018; Accepted: 18 March 2018

Citation: Filiz Okur, Zeynep Güneş. Factors Influencing Regular Mammography Screening Participation in a Sample of Turkish Women: Cross-Sectional Study. Nur Primary Care. 2018; 2(2): 1-8.

\begin{abstract}
Background: Regular mammography is important for early detection of breast cancer (BC). Women in developing countries haven't regular mammograms. There is little information about why women do not maintain regular screening schedules.
\end{abstract}

Objectives: To examine participation in regular mammography screening of women applying to cancer early diagnosis, screening and training center and identify which factors are associated with those women who participate in screening.

Methods: In the study, whose scope is cross-sectional, the archive files (14027 file) of the women applying to cancer early diagnosis center in between the years of 2004 and 2011 were evaluated. We accepted to be inclusion criteria if archives files had mammogram results. In all tests, the level of significance was set at 0.05.

Results: The mean age of participants were $50.50 \pm 8.17$ years. $91.2 \%$ were not working, $74.3 \%$ had 11 years and less education. It was determined that 52.8\% of women were in menapouse, $27.5 \%$ used oral contraseptive, $11.6 \%$ used hormone replacement therapy(HRT), $12.7 \%$ had a family history of breast cancer. 9,5\% of women had regular screening(RS). It was observed a statistically significant difference between women's RS behavior and their age, educations and job status. In further analysis, affecting factors of the RS behavior were using HRT (OR:1,481; 95\% CI:1,24-1,76), the presence of family history of BC (OR:1,613; 95\% CI:1,37-1,89), breast self-examination (BSE) (OR:1,221; 95\% CI:1,07-1,39) and suspicious mass in mammography (OR:1,263; 95\% CI:1,09-1,45). Regular mammography uses was lower for university graduates (OR:1, 324; 95\% CI:1,02-1,71).

Conclusion: Age, education, family history, received HRT, performed BSE, suspicious mass were the predictor of regular screening.

\section{Keywords}

Women, Mammography, The breast cancer risk factors, Demographic factors, Retrospective study.

\section{Introduction}

The World Health Organization (WHO)'S Global Action Report shows that number of newly diagnosed cancer cases are increasing [1]. Breast cancer is the most common cancer type among female population. Women who were newly diagnosed with breast cancer are about 1.67 million in the World in 2012 [2]. The number of newly diagnosed cancer cases was approximately 14.1 million in the World in 2012, and 6.7 million of these cases were in women. One in every four of all cancers in women according to these numbers are breast cancer. Also, breast cancer is the most common cause of cancer death among women. About 522,000 women died from breast cancer in 2012. Low- and middle-income countries have the highest incidence and mortality for BC [2]. 
Rate of $\mathrm{BC}$ is continue to increase in low and middle income countries. Breast cancer was the most common cancer among women in Turkey. Republic of Turkey Ministry of Health indicates that the incidence of $\mathrm{BC}$ has reached to 50/100,000 in the western part of Turkey [3]. WHO noticed that comprehensive cancer control plans are needed to reduce fatal malignancy progress with a late diagnosis in low-income and middle-income countries [4]. Ultrasonography and magnetic resonance images of breast are used to determine cancer. But these methods aren't population based screening programmes. Reduction in both mortality and incidence of $\mathrm{BC}$ is possible with population based screening programmes [5]. The first screening method to early determine of $\mathrm{BC}$ is mammography in developing countries. Mammography is a primary screening test because of its high sensitivity and specificity. It is also the most effective method for detecting early stage breast malignancies [6]. It is possible to reach to early diagnoses in many women with the use of breast cancer screening programs. The majority of women in the some countries are not getting regular screening as recommended [7]. Only $28.1 \%$ of Turkish women had regular mammogram. Romanian women among all European countries have the lowest proportion (13.5\%) [8].

In a study reported the least regular screeners are found in Denmark (29.3\%), Poland (40.1\%), Germany (48.2\%), Greece (47.5\%) and Switzerland (48.9\%). 89.8\% of Sweden women had 'regular mammography [9]. In a study in European countries reported that after Sweden, The Netherlands has the longest running programme and the second-highest proportion of regular screeners (84.9\%). There is different information about why women do not maintain RS schedules [6]. So, identifying the important factors influencing to maintaining RS schedules especially in low- and middle-income countries are required. Turkey has upper-middle income acording to the World Bank' classification [10]. We know the overall power of the test is strongly influenced by the size of the sample, and our research have a large sample. The results of this study will provide useful information about barriers related to maintenance of mammographic screening. Thoroughly understand influencing factors on maintenance of mammography, low and middleincome countries can be made the action plans to increasing use of screening mammography. The aim of this study was to investigate the factors influencing on regular mammography screening behavior in women.

\section{Patients and Methods}

In this study, the data were obtained by evaluating retrospectively the archive files in consulting early diagnosis, screening and training center. There was totally 14027 women's report in consulting center for between the years 2004 and 2011. We didn't evaluate between 2011 and 2013. Because early diagnosis, screening and training center didn't services in between 2011 and 2013.

\section{Design of the Study}

This study is an analytic and cross-sectional study.

Data Collection Form

The research data were obtained by "BC Patient Evaluation Form" belonging to cancer early diagnosis, screening and training center. The Information Form is related to having the risk factors of BC of the women consulting early diagnosis, screening and training center and their mammography screening. This form has three sections: The First Section has questions including information about woman's socio-demographic characteristics. The Second Section has questions about BC risk factors of women. The Third Section consists of questions related to mammography screening. For mammography screening, it was accepted as regular mammography screening if it was done at required intervals, or the women came to have mammography screening again in two years.

\section{Ethics Statement}

The research was approved by the Human Research Ethics Committees of University (protocol number: 2014/366).

\section{The Evaluation of Data}

Data Analysis: During the evaluation of data, SPSS 20 (Statistical Package for Social Sciences PASW Inc., Chicago. IL.USA) was used for statistical analysis. Help was received from a statistics expert. Results were evaluated at $95 \%$ confidence interval and at $\mathrm{p}<0.05$ significance level.

The dependent variable for logistic regression analysis was regular mammography screening. The independent variables considered in the logistic regression models were age, marital status, educational status, job status, menopausal state, parity, the state of being the first labor age over 30, breastfeeding, oral contraceptive use, the state of using hormone replacement therapy (HRT), the state of having $\mathrm{BC}$ history in the family, breast self-examination (BSE), the state of having a history of gynecological cancer or cancer suspicion, and the state of detection of a suspicious formation as a result of mammography. Missing data are excluded from analysis. Because, the rate of the missing data was very low $(<4 \%)$.

Logistic regression analysis (forward step-wise) was used to identify the predicting factors of the regular mamogram. In a first step, all items were analysed, in a second step, HRT variable was removed.

\section{Results}

It was found that the mean age of the women was $50.50 \pm 8.17$ years old, $91 \%$ of them didn't work (housewife or retired), and only $8.8 \%$ of them worked in a job. According to the results obtained from the records, it was determined that nearly all of the women were married (97\%) and had a health insurance (96\%), very few of them didn't have a social security (1.9\%) and weren't married (2.4\%); nearly three quarters of the women (74\%) received education for 11 years or less, nearly one ninth of them $(11 \%)$ received education for 12 years or more, nearly one tenth of them were illiterate, and very few of them were literate but they didn't graduate from any school (Table 1).

It is seen that $9.5 \%$ of the women consulting cancer early diagnosis, screening and training center had regular mammography screening, and most of them (90.5\%) didn't have regular screening (Table 2). 


\begin{tabular}{|c|c|c|c|}
\hline \multirow{2}{*}{\multicolumn{2}{|c|}{ Age (year) $(\boldsymbol{x} \pm$ ss) }} & \multicolumn{2}{c|}{$\mathbf{5 0 , 5 0 \pm 8 , 1 7}$} \\
\cline { 2 - 4 } & Maried & $\mathbf{n}$ & $\mathbf{\%}$ \\
\hline \multirow{4}{*}{ Marital status } & Single & 13666 & 97.4 \\
\cline { 2 - 4 } & No data & 24 & 2.4 \\
\cline { 2 - 4 } & Yes & 13509 & 0.2 \\
\hline \multirow{3}{*}{$\begin{array}{c}\text { Health } \\
\text { Insurance }\end{array}$} & No & 273 & 96.3 \\
\cline { 2 - 4 } & No data & 245 & 1.9 \\
\hline \multirow{4}{*}{\begin{tabular}{c} 
Education \\
\cline { 2 - 4 }
\end{tabular}} & Illiterate & 1376 & 9.7 \\
\cline { 2 - 4 } & Literate & 354 & 2.5 \\
\cline { 2 - 4 } & University $(\geq 12)$ & 10426 & 74.3 \\
\cline { 2 - 4 } & No data & 1570 & 11.2 \\
\hline \multirow{3}{*}{$\begin{array}{c}\text { Occupational } \\
\text { status }\end{array}$} & Employed & 1237 & 2.2 \\
\cline { 2 - 4 } & Retired or Unemployed & 12790 & 8.8 \\
\hline
\end{tabular}

Table 1: Main social and demographic characteristics of womens $(n=14027)$.

\begin{tabular}{|c|c|c|}
\hline Regular mammography & $\mathrm{n}$ & $\%$ \\
\hline Yes & 1327 & 9.5 \\
\hline No & 12700 & 90.5 \\
\hline Total & 14027 & 100 \\
\hline
\end{tabular}

Table 2: The state of having regular mammography screening of the women consulting cancer early diagnosis, screening and training center.

Table 3 includes the results of t-test (for age variable) and chisquare test concerning the comparison of the women's some characteristics according to their regular mammography screening behavior. An statistically significant difference was observed between women's regular mammography screening behavior and their age, educational, job status, menopausal status, birth number, oral contraceptive pills use, hormone replacement therapy use, breast cancer family history, breast self-examination perform, the presence or suspicion gynecological cancer and suspicious formation in mammography.

It was found that the mean age of those having regular screening was higher than those who didn't have regular screening, and the age range of those having regular screening was narrower than those having irregular mammography screening. The difference between them was found as statistically significant $(p<0,005)$. When having regular mammography screening behavior is examined, it is seen that having regular mammography screening behavior of the women receiving education for 12 years or more $(9.0 \%)$ and receiving education for 11 years or less $(9.9 \%$ is at close rates, and these rates are at lower levels in the group having no formal education $(7.9 \%)$ and being illiterate $(6.7 \%)$, and these observed differences are significant $(\mathrm{X} 2(3)=16.342 \mathrm{p}<0,001)$ (Table 3).

It is seen that while $7.6 \%$ of the women working in a job had regular screening, this rate was up to $9.6 \%$ for the women who didn't work in a job, and the observed difference was found as statistically significant $\left(\mathrm{X}^{2}(1)=5.487, \mathrm{P}<0.005\right)$ (Table 3$)$.

\begin{tabular}{|c|c|c|c|c|c|}
\hline & \multicolumn{2}{|c|}{$\begin{array}{c}\text { Regular } \\
\text { Mammography }\end{array}$} & \multicolumn{2}{|c|}{$\begin{array}{c}\text { Unregular } \\
\text { Mammography }\end{array}$} & Test- value \\
\hline $\begin{array}{c}\text { Age (year) } \\
[x \pm \mathrm{ss}),(\mathrm{n})]\end{array}$ & \multicolumn{2}{|c|}{$\begin{array}{c}51.02 \pm 7,69 \\
(1327)\end{array}$} & \multicolumn{2}{|c|}{$\begin{array}{l}50.44 \pm 8,22 \\
(12698)\end{array}$} & $\mathrm{t}=2.573^{*}$ \\
\hline Marital status & $\mathrm{n}$ & $\%$ & $\mathrm{n}$ & $\%$ & \\
\hline Maried & 1297 & 9.5 & 12369 & 90.5 & \multirow{2}{*}{$X^{2}(1)=0.536$} \\
\hline Single & 28 & 8.3 & 309 & 91.7 & \\
\hline \multicolumn{6}{|l|}{ Education } \\
\hline Illiterate & 92 & 6.7 & 1284 & 93.3 & \multirow{4}{*}{$X^{2}(3)=16.342 *$} \\
\hline Literate & 28 & 7.9 & 326 & 92.1 & \\
\hline$\leq 11$ & 1035 & 9.9 & 9391 & 90.1 & \\
\hline University ( $\geq 12$ ) & 142 & 9.0 & 1428 & 91 & \\
\hline \multicolumn{6}{|l|}{ Occupational status } \\
\hline Employed & 94 & 7.6 & 1143 & 92.4 & \multirow{2}{*}{$X^{2}(1)=5.487 * *$} \\
\hline Unemployed & 1233 & 9.6 & 11557 & 90.4 & \\
\hline \multicolumn{6}{|l|}{ Menopausal status } \\
\hline $\begin{array}{c}\text { Unregular } \\
\text { menstrual cycle }\end{array}$ & 296 & 8.6 & 3141 & 91.4 & \multirow{2}{*}{$X^{2}(2)=27.515^{*}$} \\
\hline Postmenopausal & 239 & 7.6 & 2887 & 92.4 & \\
\hline \multicolumn{6}{|l|}{ Birth number } \\
\hline Not having birth & 53 & 9.9 & 482 & 90.1 & \multirow{4}{*}{$\mathrm{X}^{2}(3)=11.344^{* *}$} \\
\hline $1-2$ & 752 & 10.1 & 6723 & 89.9 & \\
\hline $3-4$ & 413 & 8.9 & 4222 & 91.1 & \\
\hline$\geq 5$ & 89 & 7.3 & 1125 & 92.7 & \\
\hline \multicolumn{6}{|c|}{ Breastfeeding status } \\
\hline Yes & 1218 & 9.4 & 11690 & 90.6 & \multirow{2}{*}{$X^{2}(1)=0.319$} \\
\hline No & 92 & 10 & 828 & 90 & \\
\hline \multicolumn{6}{|c|}{ Using oral contraceptive } \\
\hline Yes & 392 & 10.2 & 3450 & 89.8 & \multirow{2}{*}{$X^{2}(1)=3.194$} \\
\hline No & 931 & 9.2 & 9177 & 90.8 & \\
\hline \multicolumn{6}{|c|}{ Hormone replacement therapy } \\
\hline Yes & 225 & 14.1 & 1368 & 85.9 & \multirow{2}{*}{$\mathrm{X}^{2}(1)=45.465^{*}$} \\
\hline No & 1076 & 8.9 & 11065 & 91.1 & \\
\hline \multicolumn{6}{|c|}{ Breast cancer family history } \\
\hline Yes & 244 & 13.8 & 1520 & 86.2 & \multirow{2}{*}{$X^{2}(1)=44.779 * *$} \\
\hline No & 1075 & 8.8 & 11086 & 91.2 & \\
\hline \multicolumn{6}{|c|}{ Breast self-examination } \\
\hline Yes & 816 & 10.5 & 6940 & 89.5 & \multirow{2}{*}{$X^{2}(1)=21.778^{*}$} \\
\hline No & 506 & 8.2 & 5673 & 91.8 & \\
\hline \multicolumn{6}{|c|}{ The presence/suspicion gynecological cancer } \\
\hline Yes & 189 & 12.2 & 1354 & 87.8 & \\
\hline No & 1138 & 9.1 & 11339 & 90.9 & 100 \\
\hline Abnormal mammc & ram & & & & \\
\hline Yes & 342 & 11.4 & 2646 & 88.6 & $X^{2}(1)=16327 *$ \\
\hline No & 985 & 9 & 9980 & 91 & 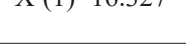 \\
\hline First pregnancy & & & & & \\
\hline$\geq 30$ & 61 & 9.2 & 603 & 90.8 & $X^{2}(1)=0050$ \\
\hline$<30$ & 1178 & 9.4 & 11291 & 90.6 & $\Lambda(1)=0.030$ \\
\hline
\end{tabular}

Table 3: The distribution of some characteristics of the women according to their regular mammography screening behavior.

Volume 2 | Issue 2 | 3 of 8 
$* \mathrm{p} \leq 0,001$ was considered statistically significant.

$* * \mathrm{p}<0.05$ was considered statistically significant.

The factors affecting regular mammography screening behavior according to logistic regression analysis results are that when it was examined in terms of educational status, it was determined that the women receiving education for 11 years or less had regular screening 1.324 times more (95\% CI 1.02-1.71) than those being illiterate, and there wasn't any significant difference between the regular mammography screening behavior of the women receiving education for 12 years or more compared to those being illiterate.

It is seen that the women who received HRT had mammography screening 1.481 times (95\% CI: 1.24-1.76) more regularly than those who didn't receive HRT, the women who had a BC history in the family had mammography screening 1.613 times $(95 \% \mathrm{CI}$ : 1.37-1.89) more regularly than those who didn't have a BC history in the family, the women who practiced breast self-examination had mammography screening 1.221 times (95\% CI: $1.07-1.39$ ) more regularly than those who didn't practice breast self-examination, and the women who were detected with a suspicious formation as a result of mammography had mammography screening 1.263 times (95\% CI: 1.09-1.45) more regularly than those who weren't detected with a suspicious formation (Table 4).

\begin{tabular}{|c|c|c|c|c|c|}
\hline & B & SE & OR & $95 \%$ & $\mathrm{CI}$ \\
\hline Age & 0.009 & 0.005 & 1.009 & 0.999 & 1.020 \\
\hline Marital status (Single) & 0.505 & 0.367 & 1.657 & 0.808 & 3.400 \\
\hline \multicolumn{6}{|l|}{ Education (Illiterate) } \\
\hline Literate & 0.176 & 0.173 & 1.192 & 0.849 & 1.675 \\
\hline$\leq 11$ & 0.281 & 0.133 & $1.324 * *$ & 1.021 & 1.718 \\
\hline University $(\geq 12)$ & -0.027 & 0.251 & 0.973 & 0.595 & 1.592 \\
\hline Occupation (Unemployed ) & 0.219 & 0.139 & 1.245 & 0.948 & 1.634 \\
\hline \multicolumn{6}{|l|}{ Menopausal status } \\
\hline \multicolumn{6}{|l|}{ Regular menstrual cycle } \\
\hline Unregular menstrual cycle & -0.152 & 0.093 & 0.859 & 0.709 & 1.040 \\
\hline Postmenopausal & 0.134 & 0.101 & 1.143 & 0.938 & 1.394 \\
\hline \multicolumn{6}{|l|}{$\begin{array}{l}\text { Birth number } \\
\text { Not having birth }\end{array}$} \\
\hline $1-2$ & -2.449 & 1.501 & 0.086 & 0.005 & 1.638 \\
\hline $3-4$ & -2.302 & 1.496 & 0.100 & 0.005 & 1.876 \\
\hline$\geq 5$ & -2.111 & 1.494 & 0.121 & 0.006 & 2.264 \\
\hline $\begin{array}{l}\text { Breastfeeding status } \\
\text { Yes }\end{array}$ & 0.234 & 0.211 & 1.264 & 0.837 & 1.910 \\
\hline $\begin{array}{l}\text { Using oral contraceptive drug } \\
\text { Yes }\end{array}$ & 0.124 & 0.068 & 1.132 & 0.990 & 1.294 \\
\hline $\begin{array}{l}\text { Hormone replacement therapy } \\
\text { Yes }\end{array}$ & 0.393 & 0.091 & $1.481 *$ & 1.240 & 1.769 \\
\hline $\begin{array}{l}\text { Breast cancer family history } \\
\text { Yes }\end{array}$ & 0.478 & 0.082 & $1.613^{*}$ & 1.373 & 1.896 \\
\hline $\begin{array}{l}\text { Breast self-examination } \\
\text { Yes }\end{array}$ & 0.200 & 0.066 & $1.221 * *$ & 1.072 & 1.391 \\
\hline $\begin{array}{l}\text { The presence/suspicion } \\
\text { gynecological cancer }\end{array}$ & 0.108 & 0.099 & 1.114 & 0.918 & 1.353 \\
\hline
\end{tabular}

Nur Primary Care, 2018

\begin{tabular}{|l|c|c|c|c|c|}
\hline $\begin{array}{l}\text { Abnormal mammogram } \\
\text { Yes }\end{array}$ & 0.233 & 0.072 & $1.263^{*}$ & 1.096 & 1.456 \\
\hline $\begin{array}{l}\text { First pregnancy } \\
\geq 30 \text { age }\end{array}$ & 0.035 & 0.171 & 1.036 & 0.740 & 1.450 \\
\hline
\end{tabular}

Table 4: The examination of the factors affecting regular mammography screening behavior with logistic regression analysis.

According to multivariate logistic regression analysis result, the factors affecting regular mammography screening behavior after the removal of HRT variable were determined as educational status, menopausal status, oral contraceptive use, BC history in the family, practicing breast self-examination, and the state of detection of a suspicious formation in the breast.

It was determined that the women receiving education for 11 years or less had mammography screening 1.358 times (95\% CI: 1.051.75) more regularly than those being illiterate, and there wasn't any significant difference between the regular mammography screening behavior of the women receiving education for 12 years or more compared to those being illiterate.

It is seen that the women who were menopausal had mammography screening 1.237 times (95\% CI: 1.02-1.5) more regularly than those menstruating regularly, the women who used oral contraceptive had mammography screening 1.150 times (95\% CI: 1.00-1.31) more regularly than those who didn't use, the women who had a BC history in the family had mammography screening 1.603 times $(95 \%$ CI: $1,36-1,88)$ more regularly than those who didn't have a BC history in the family, the women who practiced breast self-examination had mammography screening 1.244 times $(95 \%$ CI: 1.09-1.41 more regularly than those who didn't practice, and the women detected with a suspicious formation as a result of mammography had mammography screening 1.247 times (95\% CI: 1.08-1.43) more regularly than those who weren't detected (Table 5).

\begin{tabular}{|c|c|c|c|c|c|}
\hline & $\mathrm{B}$ & $\mathrm{SE}$ & $\mathrm{OR}$ & $95 \%$ & $\mathrm{CI}$ \\
\hline Age & 0.008 & 0.005 & 1.008 & 0.998 & 1.019 \\
\hline Marital status (Single) & 0.478 & 0.366 & 1.612 & 0.786 & 3.306 \\
\hline Education (Illiterate) & & & & & \\
\hline Literate & 0.215 & 0.171 & 1.240 & 0.886 & 1.735 \\
\hline$\leq 11$ & 0.306 & 0.131 & $1.358^{* *}$ & 1.050 & 1.755 \\
\hline University ( $\geq 12)$ & 0.029 & 0.243 & 1.030 & 0.640 & 1.657 \\
\hline Occupation & & & & & \\
\hline $\begin{array}{c}\text { Unemployed/retired/ } \\
\text { housewife }\end{array}$ & 0.219 & 0.137 & 1.245 & 0.951 & 1.630 \\
\hline Menopausal status & & & & & \\
\hline Unregular menstrual cycle & -0.140 & 0,097 & 0.869 & 0.719 & 1.051 \\
\hline Postmenopausal & 0.213 & 0.098 & $1.237^{* *}$ & 1.021 & 1.500 \\
\hline $\begin{array}{c}\text { Birth number } \\
\text { Not having birth }\end{array}$ & & & & & \\
\hline $1-2$ & -2.604 & 1.464 & 0.074 & 0.004 & 1.304 \\
\hline $3-4$ & -2.431 & 1.459 & 0.088 & 0.005 & 1.534 \\
\hline$\geq 5$ & -2.240 & 1.457 & 0.106 & 0.006 & 1.851 \\
\hline
\end{tabular}

Volume 2 | Issue 2 | 4 of 8 


\begin{tabular}{|l|c|c|c|c|c|}
\hline $\begin{array}{l}\text { Breastfeeding status } \\
\text { Yes }\end{array}$ & 0.178 & 0.203 & 1.195 & 0.802 & 1.781 \\
\hline $\begin{array}{l}\text { Using oral contraceptive } \\
\text { Yes }\end{array}$ & 0.140 & 0.067 & $1.150^{* *}$ & 1.008 & 1.312 \\
\hline $\begin{array}{l}\text { Breast cancer family history } \\
\text { Yes }\end{array}$ & 0.472 & 0.081 & $1.603 *$ & 1.367 & 1.880 \\
\hline $\begin{array}{l}\text { Breast self-examination } \\
\text { Yes }\end{array}$ & 0.218 & 0.066 & $1.244^{*}$ & 1.093 & 1.414 \\
\hline $\begin{array}{l}\text { The presence/suspicion } \\
\text { gynecological cancer } \\
\text { Yes }\end{array}$ & 0.184 & 0.095 & 1.202 & 0.998 & $1 ., 448$ \\
\hline $\begin{array}{l}\text { Abnormal mammogram } \\
\text { Yes }\end{array}$ & 0.221 & 0.072 & $1.247 * *$ & 1.083 & 1.435 \\
\hline $\begin{array}{l}\text { First pregnancy } \\
\geq 30 \text { age }\end{array}$ & 0.024 & 0.171 & 1.024 & 0.733 & 1.433 \\
\hline
\end{tabular}

Table 5: Regression analysis results of the factors affecting regular mammography screening behavior after the removal of HRT variable.

${ }^{*} \mathrm{p} \leq 0,001$ was evaluated at significance level. $* * \mathrm{p} \leq 0,05$ was evaluated at significance level.

Abbreviations: OR: Odds ratio, 95\% CI: 95\% confidence interval.

\section{Discussion}

It was determined in our study that the rate of the women having regular screening was rather low. Onset of BC is at early ages in Turkey and regular mammography has a strategic role in early detection of $\mathrm{BC}$ [5]. For these reasons, this finding proves the necessity of encouraging the women to have mammography screening. It was found in the study of Özmen that the rate of BC detected at Stage 1 at the time of diagnosis in Turkey was 27\% [3].

According to chi-square test results, an statistically significant difference was observed between the educational status, parity, menopausal state, HRT use, BC history in the family, practicing breast self-examination, suffering from a gynecological disease, detection of a suspicious formation in mammography and having regular mammography screening behavior of the women in our study. In further analysis, it was proved that education, HRT use, detection of a suspicious formation in mammography, practice of breast self-examination, and oral contraceptive use were important predictors of regular mammography screening behavior.

It has been reported that according to some western countries, the onset of BC in Turkey was at early ages $(40 \%$ of them under 50 years old), and cancers were detected at advanced stage [3]. It was reported that the mammography screening range was once in two years for the women aged 40-69 years [11]. Within the scope of record information evaluated in our study, it was found that the mean age of the women having regular screening (51.02 \pm 7.69 ) was higher than those having irregularly screening for mammography $(50.44 \pm 8.22)$, and the difference was significant according to t-test, but both in regression analysis made without HRT variable and made with all variables, age wasn't a factor affecting the regular mammography screening behavior. Different results were found in different studies. While age was emphasized as an important factor affecting regular mammography screening behavior in some studies [12-15]. It was proved that age wasn't a determinant factor in some studies [16-19]. Shah et al. (2014) associated the reason why different results were found about age variable in different studies with the evaluation of different age groups in different studies [20]. It can be said that our analysis studies don't resemble the study results indicating that as the age increased, the rate of having regular mammography screening decreased [21-23].The reason of this can be explained by the fact that the age of the women in our study was close to each other. It can also be explained by the fact that there wasn't a significant difference between age and regular mammography screening behavior, and age range was close to each other and the acceptance of termination age of mammography as 69 years in Turkey [11].

When the data concerning the chi square analysis result in our study was examined in terms of education, it was determined that regular mammography screening behavior. Of the women receiving education for 11 years or less was at higher levels compared to other educational levels. It was determined in the regression analysis that the women receiving education for 11 years or less had regular mammography screening more regularly changing between (1.324-1.315times) than those being illiterate, and there was a statistically significant difference between the women being at different education levels in terms of regular mammography screening behavior. It was determined that as the education levels of the women participating in the study of Demir et al. increased, the rate of having mammography screening in the last two years increased $\left[x^{2}(4)=16.231, p=0.003\right]$ [24]. Dinçel et al. conducted a survey with 300 women coming for having mammography screening, and they determined that $69 \%$ of the women received education for 11 years or less, $18.7 \%$ of them were illiterate, $7.3 \%$ of them were literate, and $4.3 \%$ of them received education for 12 years or more [25]. Sadıkoğu et al. determined in their study that the rate of having mammography screening was higher in university graduates than those being at other educational levels. It was stated in the studies carried out abroad that as the education level increased, regular mammography screening behavior increased [26-30]. It was determined in our study that the individuals were receiving education for 11 years or less had mammography screening more regularly than those receiving education for 12 years or more. It is seen that our study results didn't conform to other study results showing that as educational level increased, regular mammography screening behavior increased [15,27-32]. The reason of this difference can be explained by the fact that large majority of the women $(50.2 \%)$ that received education for 12 years or more and that we examined within our study were working in a job.

Our finding showing that the rate of having regular screening was lower at women working in job than the women not working in a job also supports our foresight. Lee and Kim stated that the women working part-time had mammography screening more regularly than the women working full-time. In the study of Gierisch et al. conducted with 576 samples aged between 43 and $49,40.7 \%$ of the women stated that not having enough time was an obstacle to having mammography screening. When the findings in chi square analysis are evaluated, it is seen that the rate of having regular screening is at rather low level in the groups which the women are 
literate but they don't have a formal education, and the women are illiterate. When this finding is taken into consideration, it can be said that the education is an important factor affecting the regular mammography screening behavior, but the education level isn't a sufficient factor alone, and job status is also an effective factor.

It was determined in the records examined within our study that more than half of the women were menopausal $(52 \%)$, and the menopausal women had regular screening significantly more (OR: $1.237 ; \% 95 \mathrm{CI}: 1.02-150)$ than the women who weren't menopausal. It was found in the study of Koralp-Durdiyeva et al. that $784(36 \%)$ of 2136 women participating in the early diagnosis and screening program carried out between the years July 2010 and July 2013 in Near East University Hospital in Turkish Republic of Northern Cyprus were in premenopausal period, and 1352 (64\%) of the women in this program were in postmenopausal period [33]. Lee and Kim (2015) determined that $59.6 \%$ of the women being menopausal had regular screening, $33 \%$ of the women who weren't menopausal had regular screening, and menopause was one of the important period in women's life, and therefore, menopause was an important factor affecting regular mammography screening behavior, and it increased the awareness of health.

It is seen that the more women got healthcare (using HRT, detection of a suspicious formation in mammography, having a history of $\mathrm{BC}$ in the family), the more women had regular screening. It is thought that the women being in touch with a doctor for any reason about health maintain their regular mammography screening behavior on doctor's probable recommendation. It was emphasized that the women being in touch with a doctor had more regular mammography screening [34], and the reason of this could be arisen from the encouragement of the doctor to the women to have mammography screening [12,34]. Coughlin and et al. reported women who had a usual source of health care were more likely to have been screened. Lee and Kim (2015) emphasized in their study that HRT use was an important factor increasing the awareness of health and affecting regular mammography screening behavior. It was determined in our study in accordance with other study results [32,34-37]. That HRT use was an important factor affecting regular mammography screening behavior. It is seen in the logistic regression analysis that the women receiving HRT had regular mammography screening 1,481 times 95\% CI: 1.24-1.76) more regularly than those who didn't receive HRT.

It was emphasized in a study that the women having a history of $\mathrm{BC}$ in their family had mammography screening 1.98 times (95\% CI: 1.20-3.25) more regularly than those not having a history of $\mathrm{BC}$ in their family, and the women being detected with a suspicious formation in the mammography had mammography screening 1,47 times 95\% CI: 1-2.16) more regularly than those not being detected with a suspicious formation in the mammography [6]. It was also determined in other studies that the women having a history of BC in their family and/or having abnormal mammography findings had mammography screening more regularly [38]. Our findings are compatible with these results. Existence of BC history in the family is very important risk factor [15]. It is seen in the logistic regression analysis that the women being detected with a suspicious formation in the mammography had mammography screening 1.263 times $(95 \%$ CI: 1.09-1.45) more regularly than those not being detected with a suspicious formation in the mammography. It was determined in the study of Sadıkoğlu et al. that the women having a history of BC in their family had mammography screening more regularly. The rate of participation of the women having a history of $\mathrm{BC}$ in their family in mammography screening increased double in the study of Carney et al. [39]. 91\% of the women having a history of BC in their family participated in mammography screening in the study of Bostean et al.

It is thought that having a history of BC in the family and having abnormal mammography findings increased the anxiety about $\mathrm{BC}$ and prompted the women to have mammography screening regularly. It was also determined in our study that $61 \%$ of the women having a history of BC in their family practised breast selfexamination. Consedine et al. [40], emphasized that on the one hand, anxiety and fear could pose an obstacle to mammography screening, but on the other hand, they were an encouraging factor for regular mammography screening.

There were 13859 women consulting cancer early diagnosis, screening and training center for mammography and we knew their parity. It was determined that $8.8 \%$ of 13859 women gave birth five times or more, $33.4 \%$ of them gave birth three or four times, $53.9 \%$ of them gave birth once or twice, and $3.9 \%$ of them were nulliparous. The difference between logistic regression analysis result and chi square analysis result revealing that there was a positive correlation between parity and regular screening can be explained with educational level [41]. It was determined in our study that the large majority of the women receiving education for 12 years or more and for 11 years or less gave birth once or twice, and the rate of giving birth three or four times and/or five or more times was high in the women at other educational levels.

It was determined in our study that $14.2 \%$ of the women having regular mammography had gynecological $\mathrm{Ca}$ or suspicion, the rate of having regular screening of the women having gynecological $\mathrm{Ca}$ or Ca suspicion was higher, and this situation was statistically significant $(\mathrm{p}<0.001)$. According to logistic regression analysis result, the existence of gynecological $\mathrm{Ca}$ or $\mathrm{Ca}$ suspicion isn't among the factors affecting regular mammography screening behavior. The reason of this can be explained by the fact that they could be sustaining their treatment in secondary and tertiary hospitals due to their existing diseases.

As the study was carried out retrospectively, only the existing records were evaluated, but some missing information in the files couldn't be evaluated. Another restriction of the study is that the reasons why the women didn't want to have regularly mammography couldn't be questioned. Also, the independent variables in the study consisted only of the existing records in the files. This situation caused the researcher not to reach different information. Therefore, we think that one-to-one survey should be 
conducted.

\section{Conclusion}

The results got from this study are the ones;

- The rate of the women having regular screening is rather low. Education is a factor affecting regular screening mammography behavior, but regular screening mammography behavior doesn't increase in parallel with the increase of education level. The majority of the women whose education level is high work in a job. The rate of having regular screening in working women is lower than those not working.

- The women going to healthcare centers more for any reason (menopause, receiving HRT, not menopausal, using oral contraceptive, and detection of a suspicious formation in mammography) have mammography screening more regularly. The women having a history of $\mathrm{BC}$ in their family have mammography screening more regularly than those not having a history of $\mathrm{BC}$ in their family.

\section{References}

1. http://publications.cancerresearchuk.org/downloads/Product/ CS_REPORT_WORD.pdf

2. Ferlay J, Soerjomataram I, Dikshit R, et al. Cancer incidence and mortality worldwide Sources methods and major patterns in GLOBOCAN 2012. Int. J. Cancer. 2014; 136: E359-E386.

3. Özmen V. Breast cancer in the world and Turkey. The Journal of Breast Health. 2008; 4: 7-12.

4. http://www.who.int/cancer/en/

5. Anderson BO, Özmen V. The challenge of breast cancer in low- and middle-income countries-implementing the breast health global initiative guidelines. Asia-Pacific Oncology \& Haematology. 2008; 1: 31-34.

6. Gierisch JM, O'neill SC, Rimer BK, et al. Factors Associated with Annual-Interval Mammography for Women in Their 40s. Cancer Epidemiology 2009; 33: 72-78.

7. Burney IA, Furrukh M, Al-Moundhri MS. What are our Options in the Fight against Breast Cancer Sultan Qaboos University Med Journal. 2014; 14: 149-151.

8. http://ec.europa.eu/eurostat/statisticsexplained/index.php/ Breastcancer_screening_statistics

9. Missinne S, Bracke P. Age differences in mammography screening reconsidered life course trajectories in 13 European countries. European Journal of Public Health. 2015; 25: 314320.

10. http://data.worldbank.org/country/turkey\#cp_wdi

11. Enginyurt Ö, Gökgöz M, Öztürk H, et al. Comparison of Opportunistic Screening and Population Based Screening Methods in the Diagnosis of Breast Cancer. ODÜ Tıp Dergisi ODU Journal of Medicine. 2014; 1: e1-e5.

12. Malley MS, Earp JA, Hawley ST, et al. The Association of Race Ethnicity, Socioeconomic Status and Physician Recommendation for Mammography Who Gets the Message About Breast Cancer Screening. American Journal of Public Health. 2001; 91: 49-54.

13. Luengo-Matos S, Polo-Santos M, Saz-Parkinson Z. Mammography use and factors associated with its use after the introduction of breast cancer screening programmes in Spain. European Journal of Cancer Prevention. 2006; 15: 242-248.

14. Wells KJ, Roetzheim R. Health disparities in receipt of screening mammography in Latinas: A critical review of recent literature. Cancer Control. 2007; 14: 369-379.

15. Kim O, Kyong O, Li CY, et al. Breast cancer screening practice and health-promoting behavior among Chinese women. Asian Nur Res. 2011; 5: 157-163.

16. Goel MS, Wee CC, Mccarthy EP, et al. Racial and ethnic disparities in cancer screening the importance of foreign birth as a barrier to care. Journal of General Internal Medicin. 2003; 18: 1028-1035.

17. Abraido-Lanza AF, chao MT, Gammon MD. Breast and cervical cancer screening among Latinas and non-Latina whites. Am Journal Public Health. 2004; 94: 1393-1398.

18. David MM, Ko L, Prudent N, et al. Mammography use. Journal of the National Medical Association. 2005; 97: 253261.

19. Lees KA, Wortley PM, Coughlin SS. Comparison of racial ethnic disparities in adult immunization and cancer screening. Am Journal Prev Med. 2005; 29: 404-411.

20. Shah V, Hernandez $\mathrm{H}$, Irene $\mathrm{NG}$, et al. An Investigation of Factors Influencing Mammography Screening Participation in British Columbia. J Cancer Prev Curr Res. 2014; 1: 00017.

21. Eisner EJ, Zook EG, Goodman N, et al. Knowledge, attitudes, and behavior of women ages 65 and older on mammography screening and medicare results of a national survey. Women Health. 2002; 36: 1-18.

22. Bancej CM, Maxwell CJ, Onysko J, et al. Mammography utilization in Canadian women aged 50-69 identification of factors that predict initiation and adherence. Canadian Journal of Public Health. 2005; 96: 364-368.

23. Kagay CR, Quale C, Smith-Bindman R. Screening mammography in the American elderly. Am Journal Prev Med. 2006; 31: 142-149.

24. Demir-Yildirim A, Özaydin AN. Sources of Breast Cancer Knowledge of Women Living in Moda İstanbul and Their Attendance to Breast Cancer Screening. J Breast Health. 2014; 10: 47-56.

25. Dinçel E, Kismet K, Erel S, et al. Factors affecting the first mammography age. The Journal of Breast Health. 2010; 6: 113-117.

26. Sadikoğlu G, Özçakir A, Doğan F, et al. Mammography Utilization among Turkish Women. Asian Pacific Journal Cancer Prev. 2010; 11: 377-381.

27. Qureshi M, Thacker HL, Litaker DG, et al. Differences in breast cancer screening rates an issue of ethnicity or socioeconomics. J Womens Health Gend Based Med. 2000; 9: 1025-1031.

28. Jones AR, Caplan LS, Davis MK. Racial ethnic differences in the selfreported use of screening mammography. Journal Community Health. 2003; 28: 303-316.

29. Sambamoorthi U, Mcalpine DD. Racial ethnic socioeconomic and access disparities in the use of preventive services among women. Prev Med. 2003; 37: 475-484.

30. Kakefuda I, Stallones L. Comparisons of Colorado womens 
cancer screening practices by residence metropolitan, nonmetropolitan, and farm. Journal Agric Saf Health. 2006; 12: 59-69.

31. Duport N, Ancelle-Park R. Do socio-demographic factors influence mammography use of French women Analysis of a French cross-sectional survey. Eur J Cancer Prev. 2006; 15: 219-224.

32. Lee $\mathrm{CH}$, Kim Y. Effects of Attitude Social Influence and Self-Efficacy Model Factors on Regular Mammography Performance in Life- Transition Aged Women in Korea. Asian Pacific Journal of Cancer Prevention. 2015; 16: 3429-3434.

33. Koralp-Durdiyeva M, Besim H, Arslan K, et al. Evaluation of Breast Cancer Cases Diagnosed In the Breast Cancer Screening Program In the Near East University Hospital of North Cyprus. J Breast Health. 2015; 11: 22-30.

34. Shields M, Wilkins K. An update on mammography use in Canada Statistics Canada. Health Reports. 2009; 20: Catalogue no. 82-003-XPE.

35. Coughlin SS, uhler RJ, bobo JK, et al. Breast cancer screening practices among women in the United States 2000. Cancer Causes Control. 2004; 15: 159-170.

36. Banks E, Beral V, Cameron R, et al. Comparison of various characteristics of women who do and do not attend breast cancer screening. Breast Cancer Research. 2002; 4: 1-6.

37. Borrayo EA, Hines L, Byers T, et al. Characteristics Associated with Mammography Screening among Both Hispanic and Non-Hispanic White Women. Journal of Women's Health. 2009; 18 .

38. Açikgöz A, Çehreli R, Ellidokuz H. Determination of Knowledge and Behavior of Women Working at a Hospital on Breast Cancer Early Detection Methods, and Investigation of Efficiency of Planned Education. Journal Breast Health. 2015; 11: 31-38.

39. Carney PA, O'Malley JP, Gough A, et al. Association between documented family history of cancer and screening for breast and colorectal cancer. Prev Med. 2013; 57: 679-684.

40. Bostean G, Crespi CM, Mccarthy WJ. Associations among family history of cancer, cancer screening and lifestyle behaviors a population-based study. Cancer Causes Control. 2013; 24: 1491-1503.

41. Consedine NS, Magai C, Krivoshekova YS, et al. Fear, anxiety, worry, and breast cancer screening behavior a critical review. Cancer Epidemiol Biomarkers Prev. 2004; 13: 501510. 